\title{
Modern Conceptions about Antibiotic Levorin A and its Derivatives Action in Cell and Bilayer Lipid Membranes
}

\author{
Dr. Samedova Arifa Ali Hasan", Dr. Sultanova Gulnar Hadjibek ${ }^{2}$ \\ Institute of Botany, Azerbaijan National Academy of Sciences, 40, Badamdart Highway. Baku AZ-1010
}

\begin{abstract}
The group of polyene antibiotics represents phytogenesis drugs with wide spectrum of application against fungal infections. Among them amphotericin B, mycoheptin, nystatin and levorin are more applicable in clinical medicine. Clinical use of these antibiotics is based on their properties. They have small toxicity and may be use together with the tetracycline group, cytostatics and other medicines because these drugs may form consecutive infection (candidiases, aspergillosis and others). Thanks to good solubility in water and adsorbability polyene antibiotics in much smaller doses are very effective and can be applied in therapeutical purposes. As chemical substances they are macrolacton compounds and their molecules contain lacton macrocyclic ring with defined number of double bonds. Nevertheless the classification of these antibiotics divides for two subdivisions: aromatic and non-aromatic ones. Aromatic antibiotics are small quantitative. These drugs have additional aromatic group. Among them more researched ones are candicidin and levorin. Hydrophobic part of a molecules has aromatic group- aminoacetophenon (1). As another polyene antibiotics levorin and its sodium salt are small toxic drugs. In the form of spray they don't cause changes of top airways, lungs and other internals.
\end{abstract}

Keywords: polyene antibiotics, bilayer lipid membranes, ionic channel, ultrasound, hemolytic activity

\section{Introduction}

Application of levorin and its sodium salt confirmed good tolerance of these drugs at treatment of candidiases of various localization. On the other hand levorin as another polyene antibiotics has a varying degree of biological activity.
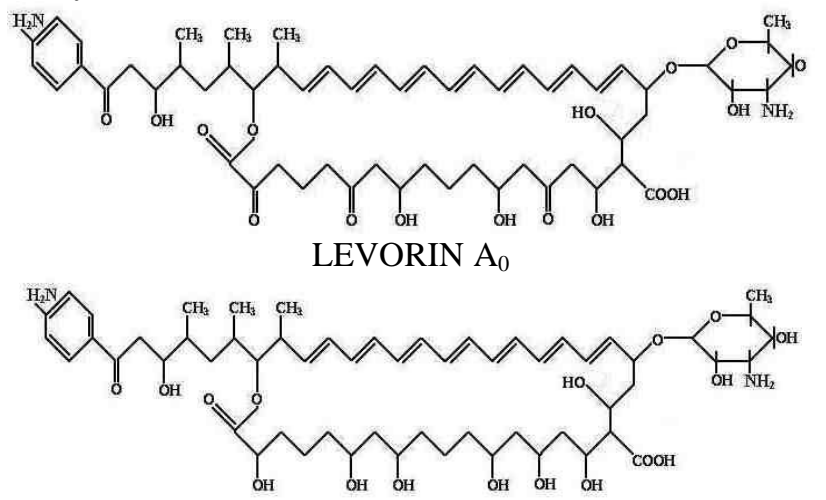

LEVORIN $\mathrm{A}_{1}$

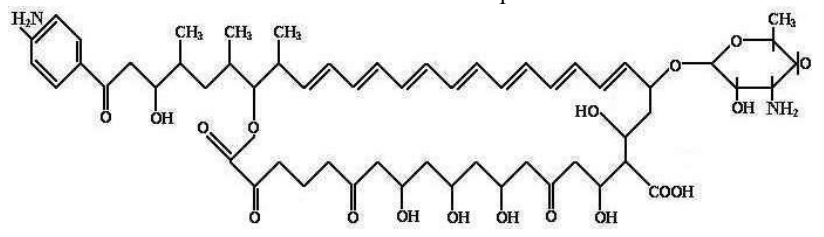

LEVORIN $\mathrm{A}_{2}$

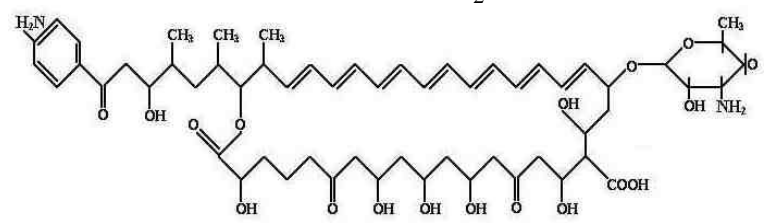

LEVORIN $\mathrm{A}_{3}$

Pic.1: Chemical structure of levorin A derivatives
Macrolactone ring of heptaene antibiotic levorin includes seven double bonds. The existence of aminoacetophenon in the molecule was established in the study of products of alkaline hydrolysis with the use of paper and thin-layer chromatography and on the base of UV-spectrum of absorbtion. Levorin contains two relative components (by chemical structure) but nonidentical aromatic heptaenes levorin $\mathrm{A}$ and levorin $\mathrm{B}$. The structure of the levorin A components in antibiotic complex was established. It is shown on Fig.(1). It is known that components differ each from other by the number of $\mathrm{OH}$-groups in molecules.

Complex structure of levorin and capability of quantity and quality changes of its biologically active substances gave the chance for needs of more detail comparative study of biological activity and toxicity. The properties of total levorin in the complex are defined most of all by the characteristics of levorin A, because this compound has more priority by quantity. There were identified five levorin A components - $\mathrm{A}_{0}, \mathrm{~A}_{1}, \mathrm{~A}_{2}, \mathrm{~A}_{3}, \mathrm{~A}_{4}$. Conductance, selectivity and properties of single ionic channels were researched and these parameters were studied on bilayer phospholipid membranes. It is was shown that biological activity of compounds decreases as $\mathrm{A}_{4}<\mathrm{A}_{3}<\mathrm{A}_{2}<\mathrm{A}_{1}<\mathrm{A}_{0}$ on Fig.(2) 


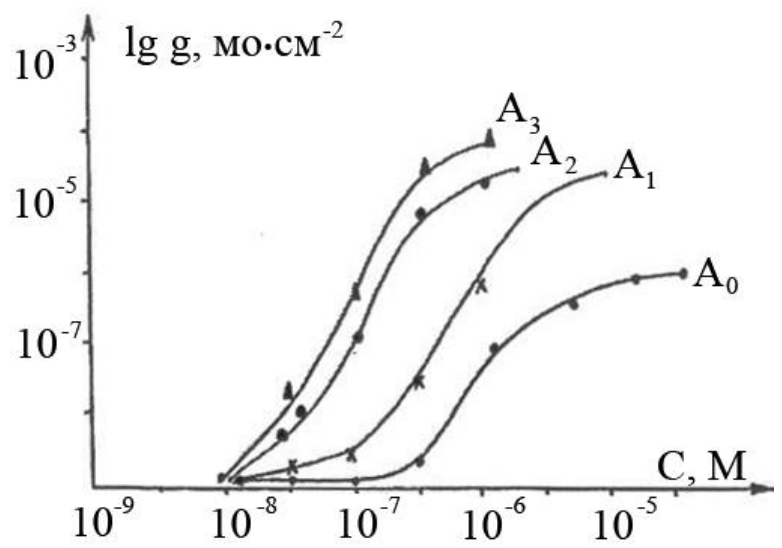

Pic.2: The dependence of bilayer lipid membranes conductance from concentration of levorin $\mathrm{A}$ individual components - $A_{0}, A_{1}, A_{2}, A_{3}, A_{4}$ added of one side of membrane.

It was shown the dependence of membrane conductance from concentration of researched levorin components. Bilayer lipid membranes were prepared from phospholipids of bull brain with cholesterol in ratio $2: 1$. Levorin $A_{3}$ has maximal efficiency but levorin $\mathrm{A}_{0}$ - minimal. Efficiency of levorin components is increasing from $\mathrm{A}_{0}$ to $\mathrm{A}_{4}$ and this fact is connected with literature results about biological activity of components. So there is correlation between action of antibiotics on cell membranes and bilayer lipid membranes. In contrast to nonaromatic heptaenes levorin's components increase membrane conductivity from one side of membrane. At the same time they have important properties. Effect of antibiotic on conductance depends not only from concentration but from the direction and value of membrane potential. If there is applied to membrane $-200 \mathrm{mV}$ from the side of antibiotic there is not increasing of membrane conductance. At the opposite direction of the field effect of one-side levorin $\mathrm{A}_{2}$ action depends of the value of electric potential. There is not fixed changes of membrane conductivity at the voltage lower than $75 \mathrm{mV}$ but there is sharp increasing of membrane conductivity at the voltage higher $75 \mathrm{mV}$. Changes of potential twice (100-200) at the constant concentration of antibiotic leads to growth of conductivity by 16 times. It needs to notice that there are two types of ionic channels assemblage at the addition of levorin from one side of membrane: potential-dependent and concentration. The first types of assemblage carry out for the electric field attached to membrane (concentration of levorin derivatives is from $10^{-8}$ till $5 \times 10^{-7} \mathrm{M}$. The second type of assemblage take place at the absence of outer electric field and depends of antibiotic concentration (more than $5 \times 10^{-7} \mathrm{M}$ ) at the constant value of membrane potential. All levorin components have cationic selectivity especially levorin $\mathrm{A}_{2}$. There were received results at the researching of interaction two different structure antibiotics - levorin $\mathrm{A}_{2}$ and amphotericin $\mathrm{B}$ added from different sides of membrane. Addition of one side of membrane anion-specific molecule (amphotericin B or nystatin) and cation-specific molecules (levorin $\mathrm{A}_{2}$ ) of another side leeds to interaction of conducting structures. Selectivity of these channels is defined by amphotericin B molecules and is not dependent from direction of gradient of penetrating ions (100 mM; 10 $\mathrm{mM} \mathrm{KCl}$ ) from the side amphotericin $\mathrm{B}$ or levorin $\mathrm{A}_{2}$, the value of membrane potential is $-23 \mathrm{mV}$. Sign of potential shows that anions are penetrating better via combined channels (Fig.3).

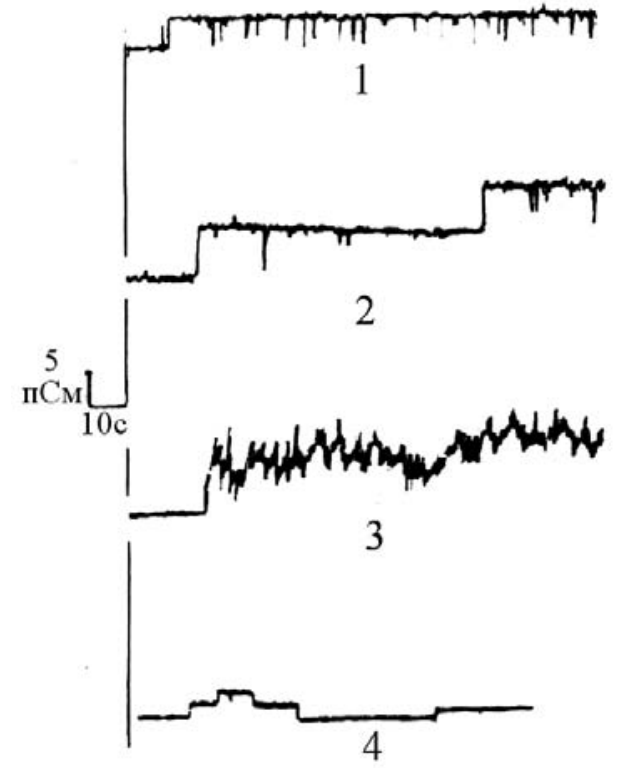

Pic.3: Single ionic channels of bilayer lipid membranes at the presense of amphotericin $\mathrm{B}$ and levorin $\mathrm{A}_{2}: 1$ amphotericin $\mathrm{B}$ from two sides of membrane; 2amphotericin $\mathrm{B}$ from one side of membrane; 3- levorin $\mathrm{A}_{2}$ from one side of membrane; 4- combined ionic channels of amphotericin $\mathrm{B}$ and levorin $\mathrm{A}_{2}$

Received data show that membranes at the presence of levorin $\mathrm{A}_{2}$ have ideal cation selectivity. Conducting unit in the membrane is asymmetric structural channel that is forming in membrane.

There are interesting information about research of polyene antibiotics on erythrocytes. The membranes of Red Blood Cells (RBC) from healthy humans are classical object for mechanism of interaction between PA and cells. Kinetic method of ultrasound hemolysis was proposed for study of modifying action of PA on membranes of RBC. It is known also that PA are capable to interact with the membranes of RBC, lymphocytes and thymocytes. There are a lot of papers about hemolytic activity of PA. But there were not researched before kinetic characteristics of PA-action on RBC-hemolysis and stability of these cells to the action of such mechanical agents like ultrasound. The research of ultrasonic hemolytic activity of RBC and their mechanical stability in the presence of PA is very actual for study of quantitative regularities of biological action of PA. The significance of research of PA-action on RBC membranes is that PA are very efficient drugs applied in medicine against fungal infections. Nevertheless we must notice that efficient use of PA in medicine is restricted by comparative toxicity for human organisms. For example, some PA (including amphotericin B) posses nephrotoxicity and hemolitic activity.

There are increasing of content of malondialdehyde (the product of lipid peroxidation) in the membranes of RBC. Its value changes in proportion to the degree of hemolysis. One of the ways of decreasing of PA toxicity is purposeful modification of PA structure. There are found that some PA had less toxicity for mammalian cells. It is also known that some of hydroxypyridin derivatives may be used in the

\section{Volume 5 Issue 4, April 2016}




\section{International Journal of Science and Research (IJSR) \\ ISSN (Online): 2319-7064 \\ Index Copernicus Value (2013): 6.14 | Impact Factor (2015): 6.391}

apparatus of artificial and support circulatory. So the study of action of amphotericin B and levorin derivatives on RBC is very important for practical use. There are researched the action of derivatives of levorin modified by amino- and carboxyl groups on ultrasound and induced haemolysis in the present paper. Modifying action of PA on RBC membranes disrupts the integrity of the cells and one of these option is hemolysis. Hemolytic effect of PA depends of antibiotics concentration that was demonstrated in the table1. We can notice ultrasound haemolytic zones: stabilization $\left(>10^{-6} \mathrm{M}\right)$, normal stage (about $10^{-5} \mathrm{M}$ ) and hemolysis $\left(<10^{-4} \mathrm{M}\right)$ for characteristics of haemolytic activity of researched antibiotics. The basic parameters like time and velocity of hemolysis are measured of researched antibiotics. The basic parameters like time and velocity of hemolysis are measured on the eksperimental curves of US-hemolysis. These properties characterize mechanical stability of RBC and changes of stability as result of RBC treatment by the described above substances. The results of eksperiments were shown in the table (1). We also study the independent action of dimethylsulfoxide on RBC stabilization during UShemolysis process. At the same time it is shown on the table1 that levoridon, and carbolevorin have their own haemolytic activity and also these drugs increase RBC UShemolysis on $30-50 \%$ in concentration $10^{-5}-10^{-4} \mathrm{M}$.

Table 1: The influence of some levorin derivatives with known molecular structure on hemolytic activity of RBC

\begin{tabular}{|c|c|c|c|c|c|c|c|}
\hline Title & $\begin{array}{l}\text { Chemical } \\
\text { Structure }\end{array}$ & $\begin{array}{c}\text { Concentration } \\
\text { of Drug }\end{array}$ & $\mathrm{t}_{\text {US-hem }}$ (seconds) & $\begin{array}{c}\% \text { of } \\
\text { stabilization }\end{array}$ & $\begin{array}{c}\% \text { of } \\
\text { stimulation }\end{array}$ & $\begin{array}{l}\mathrm{t}_{\text {lat }}-\text { latent } \\
\text { time (sec.) }\end{array}$ & $\begin{array}{l}\text { time of lysis } \\
\text { (sec.) }\end{array}$ \\
\hline Levoridon & $\mathrm{C} 65 \mathrm{H} 104 \mathrm{~N} 3 \mathrm{O} 24$ & $\begin{array}{c}10-6-5 \cdot 10-6 \\
10-5\end{array}$ & $475 \pm 19375 \pm 20$ & $\begin{array}{l}- \\
-\end{array}$ & $\begin{array}{c}5 \% \\
25 \%\end{array}$ & - & - \\
\hline Isolevoridon & $\begin{array}{c}\mathrm{C} 65 \mathrm{H} 104 \mathrm{~N} 3 \mathrm{O} 24 \\
\text { Trans-isomer of } \\
\text { levoridon }\end{array}$ & $\begin{array}{c}10-6-5 \cdot 10-6 \\
10-55 \cdot 10-5 \\
10-4\end{array}$ & $\begin{array}{l}500 \pm 25600 \pm 45525 \pm 27 \\
425 \pm 19\end{array}$ & $\begin{array}{c}- \\
20 \% \\
5 \% \\
-\end{array}$ & $\begin{array}{c}- \\
- \\
- \\
15 \%\end{array}$ & $\begin{array}{l}- \\
- \\
- \\
20\end{array}$ & $\begin{array}{l}- \\
- \\
- \\
50\end{array}$ \\
\hline Carbolevorin & $\begin{array}{c}\text { C61H94N2O24 } \\
+\end{array}$ & $\begin{array}{c}10-6-10-5 \\
5 \cdot 10-5 \\
10-4\end{array}$ & $550 \pm 27450 \pm 30290 \pm 17$ & $\begin{array}{c}10 \% \\
- \\
-\end{array}$ & $\begin{array}{c}- \\
10 \% \\
4 \%\end{array}$ & $\begin{array}{c}- \\
- \\
30\end{array}$ & $\begin{array}{l}- \\
- \\
80\end{array}$ \\
\hline Control - DMSO & $(\mathrm{CH} 3) 2-\mathrm{S}=\mathrm{O}$ & $\begin{array}{c}0,1 \% \\
0,25 \% \\
0,5 \% \\
10 \% \\
10 \%\end{array}$ & $\begin{array}{l}500 \pm 15500 \pm 17500 \pm 14 \\
500 \pm 12 \quad 650 \pm 25\end{array}$ & $\begin{array}{c}- \\
- \\
- \\
- \\
30 \%\end{array}$ & $\begin{array}{l}- \\
- \\
- \\
- \\
-\end{array}$ & $\begin{array}{l}- \\
- \\
- \\
- \\
-\end{array}$ & $\begin{array}{l}- \\
- \\
- \\
-\end{array}$ \\
\hline
\end{tabular}

At the same time some authors showed that at the combined application of US and chemical substances, last ones help to cells rehabilitation after US-action. It was also shown that electrocon ductivity of BLM and conductivity against tetraphenilborate at certain conditions with the US-action $\left(0,88 \mathrm{mHz}, 0,6 \mathrm{w} / \mathrm{sm}^{2}\right)$ together increases on $60-100 \%$. At the same time channel former PA inserts to phospholipid membrane matrix and this process approximately connects with the changes of mechanical properties of matrix and interruption of structure at the adjacent diffusion layers.

At the same time some authors showed that at the combined application of US and chemical substances, last ones help to cells rehabilitation after US-action. It was also shown that electrocon ductivity of BLM and conductivity against tetraphenilborate at certain conditions with the US-action $\left(0,88 \mathrm{mHz}, 0,6 \mathrm{w} / \mathrm{sm}^{2}\right)$ together increases on $60-100 \%$. At the same time channel former PA inserts to phospholipid membrane matrix and this process approximately connects with the changes of mechanical properties of matrix and interruption of structure at the adjacent diffusion layers. Probably PA involve to lipoprotein area may interact with hydrophobic sites of RBC membranes or these ones form structural channels in these membranes and change ionic conductivity of RBC membranes. Last conception may be proved by the results of experiments. We study the conductance of RBC membranes for nonelectrolytes because we must estimate pores diameters for polyene channels in membranes. Stabilization of RBC membrane structure under PA unfluence does not followed of membrane-linked acetylcholinesterase (ACE) inactivation, but inactivation of outer enzyme of ACE shows that inhibiting action of PA carry out of mechanical destruction of RBC membranes. Some authors in their papers showed that drugs in small concentrations stabilize membranes but in large concentrations drugs destroy these ones. Probably these drugs are adsorbed on membrane during some hours and protect this one from destruction. In this case, these drugs act against lipid and protein membranes compounds. There is a lot of cholesterol in RBC membranes. So RBC cells are sensitive against PA-action. Results are confirmed of researches of mechanism of interaction between PA and BLM on molecular level. Their biological action also may be connected with the changing of biological membranes conductance (by formation of ionic channels) for ions and organic substances with sterols of specific structure. Comparative researches of BLM and cell conductance for ions showed that PA take position in the same row by increasing efficiency of their action and this fact agree with the results of RBC US-hemolysis . So there is correlation between PA-action on cell and bilayer lipid membranes. This correlation may possible to use quantitative parameters of RBC US-hemolysis for estimation of PA biological efficiency that is very important for their application in medicine and in the analysis of combined action of US and drugs in physiotherapy. It was suggested hypothetic model of levorin channel (fig.4). On the fig.(4) channel of levorin is oligomeric structure that is consists of some molecules of antibiotics and cholesterols alternating among themselves. Molecules of antibiotics in water phase are capable to put 


\section{International Journal of Science and Research (IJSR) \\ ISSN (Online): 2319-7064 \\ Index Copernicus Value (2013): 6.14 | Impact Factor (2015): 6.391}

energetically more advantageous position and interact between each other by hydrophobic chains that leeds to formation of complexes with minimal free energy). This conception is based on the suggestion that molecules of polyene antibiotics in aqua solutions may be exist in associated forms. The includes to membrane in this form. Inclusion of molecular complex into membrane takes part in the conformation changes to the side of membrane plane.
A
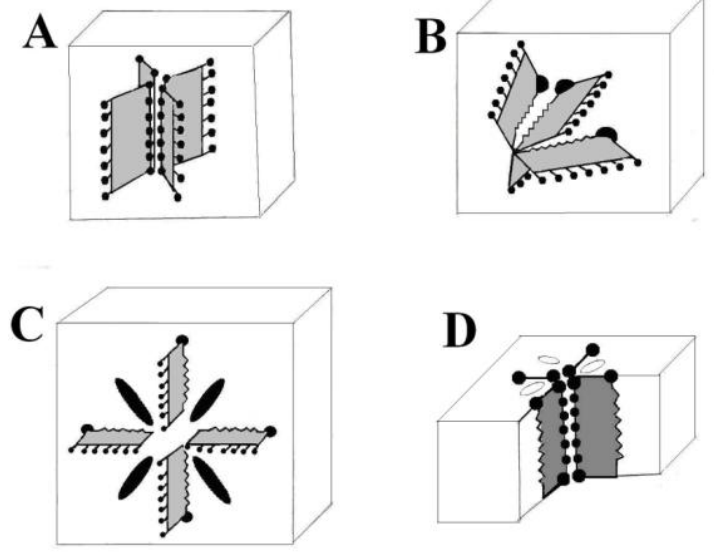

Figure 4: Hypothetic molecular model of levorin channel formation $(9,10)$.

Hydrophilic chains of antibiotics turn to the water phase but hydrophobic chains include to molecular complex on the fig.(4). This molecular complex diffuses to membrane and gradually reverse to reach energetically advantageous position. Associated structures of antibiotics in the lipid phase are thermodynamically in stabile position turn inside out. Hydrophobic "tails" of molecules create contact with lipid part of membrane. Molecules of antibiotics by hydrophobic side interact with sterol component and localize parallel membrane plane surface. Then this complex is turned inside to be out and forms ionic channel again in membrane. There are hydrophilic chains of antibiotics molecules in the channel. Thus there are formations of conducting levorin structures in lipid bilayer.

\section{Conclusion}

The detail study of levorin as another polyene antibiotics may possible to receive more advanced drugs for effective usage in practical medicine. There are results of biological action, conductivity and selectivity and RBC ultrasonic haemolysis of levorin and its derivatives represented in this review. So there is correlation in the action of researched antibiotics on cell and model bilayer membranes. It is suggested that changes of mechanical firmness of RBC under the influence of PA probably connected with microviscosity violation of protein-lipid system by formation of structural molecular sizes ionic channels.

\section{References}

[1] Akhmedli Kh.M. et al. Kinetic model of ionic channels, formed in lipid membranes by polyene antibiotics.1985. J. «Biological membranes», v..2, \#9, pp.926-933.
[2] El-Soofi S.A.F. The influence of membrane-active compounds on barrier function of cell membranes. Master's thesis .1992. Pp. 1-101

[3] Garcia - Chaumont C. et al., J. Antisence Nucleic Acid Drug Dev., 2000, v.10 (3), pp.177-184

[4] Hill K. et al (edit) "Ultrasound in medicine. Physical bases of application" Moscow. 2008. P.544.

[5] Ibragimova V.Kh. et al. Action of levorin $\mathrm{A}_{2}$ added from one side of membrane 2006. J.« Biological membranes»,v. 23, \# 6, pp.493-502. (In Russian).

[6] Kasumov Kh.M. et al. The research of interaction mechanism of individual components of levorin and nystatin with lipid membranes.1987. J. «Antibiotics amd medical biotechnology», v.32, \# 11, pp.824-828. (In Russian).

[7] Kasumov Kh.M. Structure and membrane function of polyene macrolide antibiotics.2009. Monography. Publishing house. «Nauka»-Moscow, «Elm»-Baku. (In Russian)

[8] Knopic- Scrocka A. Et al., The effect of polyene antibiotics filipin on pig red blood cells. Cell. Mol-Biol. Left.2002.,v.7. Suppl.200.

[9] Lopes Silvia C. et al. Filipin orientation revealed by linear dichroism, implication for a model of action. J. of the Amer.Chem.Society,2004. V.126,\#17,pp.53965402.

[10] Samedova A.A. Antifungal polyene antibiotics and their activity in cell and lipid membranes. 2010. J. « Achievements of medical mycology», №2, pp 43-47. (In Russian).

[11] Sultanova G.H. et al. "Hemolysis of RBC at the combined action of US waves and polyene antibiotics". J. "Antibiotics and Chemotherapy". 2007, v.52,pp.9-10. 